Meta

Journal des traducteurs

Translators' Journal

\title{
La traduction et la langue française
}

\section{Antoine Berman}

Volume 30, numéro 4, décembre 1985

URI : https://id.erudit.org/iderudit/002063ar

DOI : https://doi.org/10.7202/002063ar

Aller au sommaire du numéro

Éditeur(s)

Les Presses de l'Université de Montréal

ISSN

0026-0452 (imprimé)

1492-1421 (numérique)

Découvrir la revue

Citer cet article

Berman, A. (1985). La traduction et la langue française. Meta, 30(4), 341-342.

https://doi.org/10.7202/002063ar

Ce document est protégé par la loi sur le droit d'auteur. L'utilisation des services d'Érudit (y compris la reproduction) est assujettie à sa politique d'utilisation que vous pouvez consulter en ligne.

https://apropos.erudit.org/fr/usagers/politique-dutilisation/
Cet article est diffusé et préservé par Érudit.

Érudit est un consortium interuniversitaire sans but lucratif composé de l'Université de Montréal, l'Université Laval et l'Université du Québec à Montréal. Il a pour mission la promotion et la valorisation de la recherche. https://www.erudit.org/fr/ 


\section{LA TRADUCTION ET LA LANGUE FRANÇAISE}

ANTOINE BERMAN

Du Bellay, dans sa Défense et illustration de la langue française, réfléchit sur les divers moyens d'élargir et d'enrichir notre langue de manière à la hausser au rang des " langues cultes». Assez curieusement, il déclare à propos des traductions :

toutefois, ce tant louable labeur de traduire ne me semble moyen unique et suffisant pour élever notre vulgaire à l'égal et parangon des autres plus fameuses langues.

La postérité a malheureusement déformé ce jugement critique, mais équilibré, et en a fait une condamnation de la traduction : celle-ci ne saurait contribuer à un véritable élargissement de notre langue.

Et pourtant, le français - classique et moderne - ne serait pas ce qu'il est si la traduction ne l'avait continûment enrichi, enrichi du point de vue lexical, syntaxique, enrichi, surtout, du point de vue de la souplesse expressive et de sa capacité à articuler les idées.

Déjà du seul point de vue lexical (ou "terminologique ") la contribution des traducteurs dans ce domaine a été absolument décisive. Et cela très tôt. Dès le Xrve siècle, Nicolas Oresme, évêque de Lisieux et traducteur d'Aristote, introduit en français une foule de mots : "abstinence ", " affinité ", " arbitrage ", " aristocratie ", " bénévole ", " combinaison ", " condensation ", " conditionnel ", " contingent ", " corruption ", " diffamer ", etc. On lui doit également l'expression " langue maternelle" : celle-ci est la langue que parlent les "mères", et elle s'oppose à la langue des doctes, le latin.

Au XVI ${ }^{e}$ siècle, Du Bellay lui-même (qui a traduit entre autres une partie de l'Énéide de Virgile) nous donne le mot " patrie ". Mais c'est surtout Amyot qui résume l'effort des traducteurs de son siècle, notamment par sa monumentale traduction de Plutarque. Si Saint-Jérôme est le patron de tous les traducteurs du monde entier, Amyot mérite de devenir celui des traducteurs français. Montaigne - qui lui doit énormément - loue en lui « la naïveté et pureté du langage, en quoi il surpasse tous les autres».

Gustave Lanson écrit très justement à son propos :

Mais il suffit de songer que l'œuvre de Plutarque est une véritable encyclopédie, et l'on comprendra quel exercice cette traduction a été pour la langue, combien elle s'en est trouvé assouplie et enrichie. Il a fallu, pour exprimer une telle diversité de choses, faire appel à toutes les ressources du français ; il a fallu en élargir les moules et les formes par toutes sortes d'analogies et d'emprunts, italianismes, hellénismes, latinismes. Nombre d'idées et d'objets étaient pour la première fois désignés et définis en français : il a fallu trouver et créer des mots'.

En effet, Amyot a introduit des termes comme " atome ", " enthousiasme ", "gangrène ", " horizon ", " prosodie ", "pédagogue ", " nuage ", " hiéroglyphe ", " misanthrope", etc. Lanson ajoute ceci, qui est décisif :

En somme, venant après le Pantagruel de Rabelais, après l'Institution de Calvin, le Plutarque d'Amyot est le plus considérable effort fourni par la langue française dans sa tentative d'égaler les langues anciennes il rend Montaigne possible. Mieux même encore que les $E$ ssais, il est le plus complet et copieux répertoire des tours, locutions et mots que la langue du $\mathrm{XVI}^{\mathrm{e}}$ siècle a mis à la disposition de la pensée. Vaugelas et Fénélon, dans le siècle suivant, lui ont bien rendu cette justice ${ }^{2}$. 
Faisons le compte : des trois œuvres majeures qui ont créé au XVI $I^{e}$ siècle la langue française ${ }^{3}$, deux sont des traductions : celle d'Amyot, on vient de le voir, et l'Institution de Calvin, car il s'agit d'une " auto-traduction " du latin. Et le Pantagruel lui-même contient de nombreuses francisations de termes latins, grecs, etc. Le rôle de la traduction dans la constitution de notre langue n'est donc pas à démontrer : l'étonnant, c'est qu'on le méconnaisse encore.

Et ce mouvement s'est poursuivi ultérieurement. Preuve en est la traduction des Mille et une nuits par Galland, à l'orée du XVIII' siècle, dont Alain, dans ses Propos, a pu dire qu'elle a rendu le style de Montesquieu ou de Voltaire possible, avec tout l'engouement pour l'orientalisme.

Rivarol, qui a traduit l'Enfer de Dante, a mieux que personne défini ce rôle de la traduction :

les traductions ... perfectionnent le langage. En effet, la langue française ne recevra toute sa perfection qu'en allant chez ses voisins pour commercer et pour reconnaître ses vraies richesses. (...) La traduction seule lui rendra de tels services. Un idiome étranger, proposant toujours des tours de force à un habile traducteur, le tâte pour ainsi en tous sens ; bientôt il sait tout ce que peut ou ne peut pas sa langue ; il épuise ses ressources, mais il augmente ses forces, surtout lorsqu'il traduit les ouvrages d'imagination, qui secouent les entraves de la construction grammaticale, et donnent des ailes au langage. ${ }^{4}$ (Discours préliminaire à la traduction de l'Enfer, Paris, Didot, 1783.)

On retrouverait de tels jugements sur la traduction au XIX ${ }^{e}$ siècle, notamment chez Victor Hugo.

$\hat{A}$ la fin du XXe siècle, ces appréciations n'ont rien perdu de leur valeur. Plus enocre : la langue française étant placée face au défi que constitue l'expansion de l'angloaméricain, la traduction peut jouer ici le rôle d'une véritable barrière protectrice, surtout dans le domaine des sciences et de la technologie. Moins l'on traduira la production " technologique " anglo-américaine, plus les chercheurs, les ingénieurs et les techniciens auront tendance à délaisser le français et à parler, lire et écrire en anglais. Le domaine terminologique est placé devant le même problème : soit traduire les termes étrangers conformément aux exigences du langage technique et à celles de l'esprit de notre langue, soit se laisser envahir par une masse indiscriminée de vocables étrangers, se laisser dominer par l'afflux des mots empruntés ou mal francisés.

C'est là, bien entendu, une situation qu'ignoraient Amyot, Rivarol ou Hugo.

D'où l'urgence d'une véritable politique de la traduction et de la terminologie. La chose en elle-même n'est pas si nouvelle qu'on le pense : la plupart des grandes traductions du XVIe siècle ont été commandées et patronnées par les rois, et notamment par François $I^{e r}$. Cette politique royale de la traduction a d'ailleurs été étudiée en détail par les historiens : on sait par exemple quelles traductions du grec, du latin et de l'hébreu (les " langues reines ", disait Cervantes) étaient directement patronnées par le roi, tandis que celles de l'espagnol, de l'italien, etc., relevaient des autres membres de la famille royale ou des Grands de la Cour.

Développer, dans le cadre de la promotion de la langue française, une politique de la traduction est donc un impératif moderne, répondant à des nécessités linguistiques, culturelles, scientifiques, économiques nouvelles, et la poursuite d'une tradition très ancienne, qu'il convient de ne pas oublier.

Notes

1. Histoire de la langue française, Paris, Hachette, pp. 273-279.

2. Ibid.

3. Et pas seulement littéraire : politique, juridique, scientifique, religieuse.

4. Ce texte, on le voit, précède d'un an, le Discours sur l'universalité de la langue française (1784). 